\title{
Solunum Hastalıkları ile İlişskili Semptom Seslerinin Sınıflandırılması
}

\author{
Mesut Melek \\ Gümüşhane Üniversitesi, Gümüşhane Meslek Yüksekokulu, Elektronik ve Otomasyon Bölümü, Gümüşhane, Türkiye, (ORCID: 0000-0002-7152-7788), \\ mesutmelek@gumushane.edu.tr
}

(1st International Conference on Applied Engineering and Natural Sciences ICAENS 2021, November 1-3, 2021)

(DOI: 10.31590/ejosat.999265)

\begin{abstract}
ATIF/REFERENCE: Melek M. (2021). Solunum Hastalıkları ile İlişkili Semptom Seslerinin Sınıflandırılması. Avrupa Bilim ve Teknoloji Dergisi, (28), 333-337.

Öz

Covid-19 gibi solunum yolu enfeksiyonlarının erken tespiti, hastalı̆̆ın daha kolay tedavisine ve hastanın daha rahat bir süre geçirmesine yol açarak ciddi komplikasyon olasılı̆̆ını azaltabilir. Öksürme ve hapşırma gibi solunum seslerinin sıklığı, şiddeti ve türü (kuru veya balgamlı), hastalığın teşhisi, tedavisi ve davranışlarının tespitinde tıp uzmanları için çıkarılabilen zengin bilgiler taşımaktadır. Bunun için, makine veya derin öğrenimine dayalı otomatik yaklaşımların geliştirilmesi oldukça önemlidir. Center for Open Science (OSFHOME), 2020 yılında güncellediği veri küme üzerine, bu alanda çalışan araştırmacıları, ses kayıtlarını kullanarak hastalık seslerinin otomatik algılanması için makine öğrenimi modelleri oluşturmaya davet etti. Veri seti, "Pfizer Digital Medicine Challenge" için oluşturulmuştur ve amacı öksürme ve hapşırma gibi seslerinin tespiti için makine öğrenimi modellerinin geliştirilmesidir. Veri seti üç parçaya ayrılmıştı;; eğitim, doğrulama ve test kümeleri. Sunulan çalışmada, bu veri seti üzerine yeni bir makine öğrenimi sistemi önerildi. Eğitim, doğrulama ve test örneklerinden öznitelikler elde edildikten sonra, dört farklı sınıflandırıcının parametrelerini hesaplamak için doğrulama veri kümesi kullanıldı ve son aşamada test veri kümesi üzerine sınıflandırma gerçekleştirildi. Elde edilen sonuçlara göre, radyal tabanlı çekirdek fonksiyonlu destek vektör makine (DVM) sınıflandırıcısı solunum seslerini diğer seslere karşı, \%76 civarında bir doğruluk oranıyla diğer sınıflandırıcılara göre daha başarılı sınıflandırdı.
\end{abstract}

\section{Classification of Symptom Sounds Associated with Respiratory Disease}

\begin{abstract}
Early detection of respiratory infections such as Covid-19 can lead to the easier treatment of the disease and a more comfortable time for the patient, reducing the likelihood of serious complications. The frequency, severity, and type (dry or phlegm) of respiratory sounds such as coughing and sneezing carry a wealth of information that can be extracted for medical professionals in diagnosing the disease, treating it, and determining its behavior. For this, it is very important to develop automated approaches based on machine or deep learning. Center for Open Science (OSFHOME) invited researchers working in this field to create machine learning models for automatic detection of the disease sounds using sound recordings, based on the dataset it updated in the 2020 year. The dataset was created for the "Pfizer Digital Medicine Challenge" and its purpose is to develop machine learning models for detecting sounds such as coughing and sneezing. The dataset is divided into three parts; training, validation, and test sets. In the presented study, a new machine learning system is proposed on this dataset. After the features were obtained from the training, validation, and test samples, the validation dataset was used to calculate the parameters of the four different classifiers, and in the final stage, the classification was performed on the test set. According to the results, the radial-based kernel function support vector machine (RBF-SVM) classifier classified respiratory sounds against other sounds more successfully than other classifiers with an accuracy rate of around $76 \%$.
\end{abstract}

Keywords: Respiratory sounds, Classification, Machine learning, COVID-19, Cough, Sneeze. 


\section{Giriş}

Solunum yolu hastalıkları dünyada önde gelen ölüm nedenlerinden biridir. Dolaysıyla, bu hastalıkların doğru ve erken teşhisi ve değerlendirilmesi son derece önemlidir. Solunum seslerinin otomatik analizi, son yıllarda büyük bir araştırma alanı olmuştur [1]. Solunum hastalıklarıyla ilişkili semptom seslerinin otomatik sınıflandırılması, solunum fonksiyon bozukluğunun erken evrelerindeki anormallikleri tespit etme ve böylece karar vermenin etkinliğini artırma potansiyeline sahiptir [2]. 2019 yılının son aylarında dünya çapında yayılan, ölümcül COVID-19 hastalığı da solunum yollarından aşağı inerek akciğerlere zarar veriyor ve şiddetli akut solunum sendromuna neden oluyor. En erken belirtilerinden biri öksürük olan bu hastalığın nedeni ise insan oğlunun karşılaştığ 1 en bulaşıcı virüs türlülerinden biri olan korona virüsüdür [3]. Bunun için, bahsedildiği gibi, öksürük ve hapşırmak gibi solunum hastalıkları ile ilişkili semptom seslerinin otomatik sınıflandırılması günümüzde daha da önemli hale gelmiştir.

Literatürde, öksürük sesi tanıma üzerine yapılan birçok çalışmaya rastlamaktayız. Bu çalışmaların bazıları öksürük sesinin diğer seslerden ayrıt edilmesi üzerine yapılırken, bazıları ise öksürük türlerinin sınıflandırmasına yönelik yapılmıştır. Genel olarak, bu çalışmalarda, öksürük seslerinin sinyal işleme analizi yoluyla sınıflandırılabileceği gösterilmiştir.

Öksürük türlerinin sınıflandırması üzerine yapılan bir çalışmada, Abeyratne ve ark. [4] pnömoni, astımlı ve bronşit öksürüklerindeki farklılıkları analiz ettiler ve görselleştirdiler. Bu çalışmada, öksürükler pnömoni veya pnömoni olmayan öksürükler olarak iki sınıfa ayrıldı. Sınıflandırıcı olarak lojistik regresyon modeli oluşturuldu ve zaman serisi istatistikleri, formant-frekans takibi ve genel zamansal-spektral enerji tabanlı özelliklerin bir kombinasyonunu kullandı. Sistemin hassasiyeti \%94 ve özgüllüğü \%75 elde edildi. Swarnkar ve ark. [5] tarafindan sunulan bir çalışmada, öksürük sesleri ıslak veya kuru olarak ikiye ayrıldı. Çalışmada, Spektral enerji, zamansal zarf ve basıklık gibi zamandan bağımsız dalga formu istatistikleri olmak üzere çeşitli sinyal işleme yöntemleri kullanıldı. Al-khassaweneh ve Abdelrahman [6] tarafindan yapılan bir çalışmada, astımlı hastaların öksürükleri, astımlı olmayan hastalarınkilerden farklı enerji imzasına sahip olduğu kanıtlandı. 2011 yılında yapılan bir çalışmada [7], öksürük seslerini analiz etmek ve kuru ve islak öksürük seslerini ayırt etmek için kullanılabilecek iki özellik tanımlanmıştır. $\mathrm{Bu}$ özellikler, enerji zarfının tepe sayısı ve öksürük sinyalinin ikinci fazının iki frekans bandının güç oranıdır. Ancak sadece sekiz kuru ve sekiz ıslak öksürük sesi kullanılarak net bir ayrım gözlemlendi. Yakın zamanda yapılan bir çalışmada [8], 131 denekten akıllı telefonlar tarafından toplanan öksürük sesinin akustik özelliklerine dayanan objektif bir yaklaşım önerilmiştir. Islak ve kuru öksürük sınıflandırması için sistemin duyarlılı̆̆1 \%88 ve özgüllüğü \%86 olarak hesaplandı.

Öksürük tespiti yapan sistemler için de birçok çalışma mevcuttur. [9]' de gürültülü bir ortamda öksürüklerin tespiti için bir ön işleme yöntemi önerilmiştir. Ön işleme aşamasında dördüncü dereceden bir Butterworth yüksek geçiş filtresi kullanılarak, DVM sınıflandırıcısıyla öksürük seslerinin otomatik analizi için bir metodoloji sunuldu. [10]' da, ön işleme aşamasında bir akustik başlangıç detektörü kullanan bir öksürük tespit sistemi önerilmiştir. Uzun-kısa süreli-bellek derin sinir ağı mimarisine dayanan bu sistem, \%90 duyarlılık ve \%99 özgüllüğe sahiptir. Barata et al. [11], çeşitli mobil cihazlarda mevcut öksürük e-ISSN: 2148-2683 algılama modellerinin ölçeklenebilirliğini sağlamak için bir çalışma yürütmüştür. Yazarlar, 43 denekle yapılan bir laboratuvar çalışmasında 5 farklı kayıt cihazı ile 6737 öksürük örneği ve 8854 kontrol sesi kaydederek cihazlar arasında farklı yöntemlerin performansını araştırdı. Cihazlar arası çakışmayı azaltmak için verimli bir evrişimli sinir ağı mimarisi ve topluluk tabanlı bir siniflandirıci kullanarak, \%85,9 ile \%90,9 arasında ortalama doğruluk elde edildi. Önerilen yöntemler, cihazlar arasında tutarlılık, ölçeklenebilirlik ve cihazdan bağımsız öksürük tespitini kanıtlamaktadır.

Bu çalışmada, Center for Open Science (OSFHOME) [12] tarafindan hazırlanan ve 2020 y1lında güncellenen veri seti [13] üzerine, yeni bir makine öğrenimine dayalı öksürük ve hapşırma sesi tespit sistemi önerildi. OSFHOME bu alanda çalışan araştırmacıları bu veri kümesini kullanarak, hastalık seslerinin otomatik algılanması için makine öğrenimi modelleri oluşturmaya davet ediyor. Veri seti, "Pfizer Digital Medicine Challenge" için oluşturulmuştur ve eğitim, doğrulama ve test veri kümeleri olarak, üç parçaya ayrılmıştır. Eğitim, doğrulama ve test örneklerinden öznitelikler elde edildikten sonra, dört farklı sınıflandırıcının parametrelerini hesaplamak için doğrulama veri kümesi kullanıldı ve son aşamada test veri kümesi üzerine sınıflandırma gerçekleştirildi. Daha önce bu veri seti üzerine yapılan bir çalışma olmadığından ve literatür taraması yapıldığında hapşırma ve öksürük sesleri aynı sınıfta diğer seslere karşı sınıflandırılmadığından, ilk kez bu çalışmada, öksürük ve hapşırma sesleri aynı sınıfta diğer seslere karşı sınıflandırılıyor. Böylece, önerilen öksürük ve hapşırma seslerini tespit eden sistem, havaalanlarında, otobüslerde, hastanelerin bekleme salonlarında, huzurevlerinde ve benzeri kalabalık ortamlarda kolaylıkla bir tarama yöntemi olarak kullanılabilir.

Çalışmanın devamı bu şekilde sıralandı; kullanılan malzemeler ve yöntemler ikinci bölümde, ve bulgular ve tartışma üçüncü bölümde sunuldu. Sonuç bölümlü ise, dördüncü bölümde getirildi.

\section{Malzemeler ve Yöntemler}

\subsection{Veri Seti}

"Solunum hastalığı ile ilişkili semptom seslerinin veri seti" adıyla sunulan açık erişimli veri seti [13], Center for Open Science (OSFHOME) tarafindan Pfizer Digital Medicine Challenge için oluşturulmuştur. Center for Open Scince (OSFHOME) bu veri seti üzerine araştırmacıları meydan okumaya davet ediyor. Farklı veri setlerinden toplanan bu veri seti, hasta ve hasta olmayan etiketlerle iki sınıfa ayrılmıştır. Hasta sınıfı daha çok hapşırma ve öksürme gibi solunum hastalığı ile ilişkili semptom seslerini içerirken, hasta olmayan sınıftaki sesler daha çok gülme, konuşma, şark1 söyleme gibi, insan kaynaklı, günümüzde etrafımızda duyduğumuz sesler içermektedir. Kayıtlar 4.98 saniye boyunca $44100 \mathrm{~Hz}$ örnekleme frekansıyla kaydedilmiştir. Sınıflardaki örnek dağılımı Tablo 1' de verilmiştir. Göründüğü gibi, çalışmalar arasında adil bir karşılaştırma yapılabilmesi için veri seti eğitim, doğrulama ve test olarak üç parçaya bölünmüştür.

Tablo 1. Sinıflar arasında örnek dă̆ılımı

\begin{tabular}{|c|c|c|c|}
\hline & Hasta & Hasta olmayan & Toplam \\
\hline Ĕ̈itim & 1435 & 2283 & 3718 \\
\hline Doğrulama & 468 & 753 & 1221 \\
\hline Test & 642 & 1012 & 1654 \\
\hline
\end{tabular}




\subsection{Mel-frekans kepstral katsayıları (MFCC)}

MFCC tekniği, insan kulağının frekans bandının değişimi ile uyumlu olduğu bilinmektedir [14], [15]. Ayrıca, MFCC ses tanıma sistemlerinde diğer tekniklere göre daha başarılı olduğu kanıtlanmıştır [16], [17]. MFCCs tekniği kuru ve 1slak öksürük ayrımında faydalı bir yöntem olduğu Chatrzarrin ve ark. tarafından 2011 yılında gösterildi. Yakın zamanda yapılan bir çalışmada [18] Covid-19 öksürük sesleri Covid-19 olmayan öksürük seslerinden ayrıt edilmesi için, MFCC yöntemiyle öznitelikler elde edildi ve DVM sınıflandırıcısı ile sınıflandırıldı. MFCC'nin çalışma prensibi kısaca sinyal pencereleme, hızlı Fourier dönüşümü (DFT) uygulaması, katsayıların büyüklüğünün logaritmasının hesaplanması, frekansları bir mel ölçeğine çarpıtma ve ayrık kosinüs dönüşümü (DCT) uygulaması olarak özetlenebilir [19]. Mel spektrumu, bir dizi bant geçiren filtreden geçen Fourier dönüşümünden elde edilen sinyale dayalı olarak hesaplanır. Mel ölçeği ile frekans ölçeği arasındaki dönüşüm, aşağıda verilen denklem ile sağlanmaktadır.

$\operatorname{mel}(f)=2595 \times \log \left(1+\frac{f}{700}\right)$

\subsection{Sinıflandirıcılar}

Sınıflandırma işleminde, bir sınıflandırıcı belirli etiketlere sahip örneklerle eğitilir ve bir model oluşturulur. Böylece, oluşturulan model, bilinmeyen örneklerin etiketini tahmin etmek için kullanılır [20]. Öksürük seslerinin sınıflandırılmasında Lojistik regresyon (LR), destek vektör makineleri (DVM), çok katmanlı algılayıcılar, evrişimli sinir ağları, uzun kısa süreli bellek (LSTM) ve artık tabanlı sinir ağı mimarisi [21], gibi makine ve derin öğrenme yöntemlerine dayalı birçok sınıflandırıcı kullanılmıştır. Bu çalışmada, AdaBoost-Ensemble, radyal tabanlı çekirdek fonksiyonlu DVM (RTF-DVM), Polinomiyal çekirdek fonksiyonlu DVM (Polinomiyal-DVM) ve Karar ağacı sınıflandırıcıları, öksürük ve hapşırma seslerini diğer seslerden ayrıt etmek için kullanıldı.

\section{Araştırma Sonuçları ve Tartışma}

Makine öğrenimine dayalı, öksürme ve hapşırma gibi solunum hastalıklarının semptomlarının ses kayıtları diğer seslere karşı sınıflandırılması, OSFHOME tarafından sunulan açık erişimli veri seti üzerine gerçekleştirildi. Öznitelikler, MFCC yöntemi kullanılarak kayıtlı seslerden çıkarıldı ve dört farklı sınıflandırıcı ile sınıflandırıldı. Öznitelik çıkarma ve sınıflandırma süreçlerinde farklı parametreler mevcuttur. $\mathrm{Bu}$ parametrelerin en uygun değerlerini seçmek için deneme yanılma yöntemi kullanıldı. Ancak, öznitelik çıkarma aşamasında, MFCC katsayı sayısı ve sınıflandırma aşamasında, sınıflandırıcıya ayıt parametrenin belirlenmesi için doğrulama veri kümesi kullanıldı. Böylelikle, farklı parametrelerle elde edilen doğruluk oranları kıyaslanarak, bahsedilen parametreler için en uygun değerler seçildi.

Bir ses kaydı için MFCC hesaplandığında, $\mathrm{M} \times \mathrm{N}$ boyutunda bir matris elde edilir; burada M, MFCC katsayıları sayısı ve N, pencerelerin sayısıdır. $\mathrm{Bu}$ çalışmada, pencere türü Hamming ve pencere uzunlukları 1536 örnek örtüşmeyle 2048 örnek seçildi. $\mathrm{Bu}$ seçimler deneme ve yanılma metoduyla elde edildi. Ancak, En uygun katsayı sayısını belirlemek için 12, 13, 14, 24, 26, ve 28 sayıları arasında doğruluk oranı aracılığıyla, bir kıyaslama yapıldı. MFCC tekniğini kullanan çalışmaların birçoğunda katsayı genelde 13 olarak seçilmiştir, bunun için bu çalışmada bu sayının katsayıları ve komşuları kıyaslama aşaması için seçildi. MFCC katsayıları elde edildikten sonra, her katsayı dizini için ortalama, standart sapma ve ortalama karekök değerleri hesaplandı ve böylelikle öznitelik vektörünün boyutu $\mathrm{M} \times 3$ (örneğin 13 katsayısı için $13 \times 3=39$ ) oldu. $\mathrm{Bu}$ aşamada, sınıflandırıcı parametrelerinin değerleri sabit tutularak Tablo 2' de elde edilen sonuçlarla birlikte verilmiştir.

Tablo 2' de göründüğü gibi, RTF-DVM sınıflandırıcısı 28 MFCC katsayısı kullanıldığında, en yüksek Doğruluk oranına (0.7703) ulaşmıştır. Bunun için çalışmanın devamında, bu sınıflandırıcının sigma parametresinin belirlenmesi için, 0.1-2 arasında 0.2 adımlarla tarama yapıldı. Sonuçlar Tablo 3' de verilmiştir. Doğruluk oranının yanında, her sigma için, sınıfların hassasiyeti ve özgüllüğü de hesaplandı. Tablo 3' de göründüğü gibi, sigmanın değeri 1.3 olduğunda, daha yüksek doğruluk oranı elde edilmiştir. Sistemin hassasiyeti ve özgüllüğü de bu değerde diğer sigmalara göre yüksek görünmektedir.

Tablo 1. Farklı MFCC katsayıları için sınıflandırma sonuçları

\begin{tabular}{c|c|c|c|c}
\hline $\begin{array}{c}\text { MFCC katsayı } \\
\text { sayısı }\end{array}$ & AdaBoost-Ensemble & RTF-DVM & Polinomiyal -DVM & Karar ağacı \\
\cline { 2 - 5 } & Maksimum Bölme Sayısı =20 & Sigma =1 & Sigma =1 & Maksimum Bölme Sayısı =100 \\
\hline 12 & 0.7358 & 0.7449 & 0.7096 & 0.6874 \\
\hline 13 & 0.7490 & 0.7465 & 0.7326 & 0.6965 \\
\hline 14 & 0.7514 & 0.7473 & 0.7096 & 0.7014 \\
\hline 24 & 0.7588 & 0.7662 & 0.7170 & 0.6883 \\
\hline 26 & 0.7514 & 0.7678 & 0.7252 & 0.6866 \\
\hline 28 & 0.7531 & 0.7703 & 0.7309 & 0.6825 \\
\hline
\end{tabular}


Böylelikle, önerilen sistemde, öznitelik çıkarma aşamasında MFCC katsayısının sayısı ve sınıflandırıcının türü ve parametresi seçildikten sonra, önerilen sistemin performansı test kümesi üzerinde ölçüldü ve elde edilen sonuçlar Tablo 4' de bir araya getirildi. Sistemin doğruluk oranı 0.76 civarında hesaplanırken, sistemin hassasiyeti ve özgüllüğü de sirasıyla, 0.82 ve 0.65 civarında elde edildi.

Tablo 3. RTF-DVM sınıflandırıcısında farklı sigma değerleri için sınıflandırma sonuçları

\begin{tabular}{|c|c|c|c|}
\hline Sigma & Doğruluk Oranı & Hassasiyet & Özgüllük \\
\hline 0.1 & 0.7358 & 0.8896 & 0.4882 \\
\hline 0.3 & 0.7465 & 0.8657 & 0.5546 \\
\hline 0.5 & 0.7490 & 0.8670 & 0.5589 \\
\hline 0.7 & 0.7547 & 0.8617 & 0.5824 \\
\hline 0.9 & 0.7687 & 0.8630 & 0.6167 \\
\hline 1.1 & 0.7703 & 0.8644 & 0.6188 \\
\hline 1.3 & $\mathbf{0 . 7 7 2 8}$ & $\mathbf{0 . 8 5 7 7}$ & $\mathbf{0 . 6 3 6 0}$ \\
\hline 1.5 & 0.7728 & 0.8524 & 0.6445 \\
\hline 1.7 & 0.7662 & 0.8537 & 0.6253 \\
\hline 1.9 & 0.7711 & 0.8577 & 0.6317 \\
\hline
\end{tabular}

Tablo 4. Önerilen sistemin test veri kümesi üzerindeki sonuçlar

\begin{tabular}{|c|c|c|c|}
\hline & $\begin{array}{c}\text { Doğruluk } \\
\text { Oranı }\end{array}$ & Hassasiyet & Özgüllük \\
\hline$R T F-D V M$ & 0.7581 & 0.8230 & 0.6458 \\
\hline
\end{tabular}

Önerilen sistem bir uygulama olarak akıllı telefonlara kurulabilir veya daha öncede söylendiği gibi, kalabalık ortamlarda bir tarama aracı olarak kullanılabilir. Diğer taraftan, elde edilen sonuçların kıyaslanması için, literatüre bakıldığında bu veri seti üzerine herhangi bir çalışmaya rastlamamaktayız. Ancak elde edilen sonuçlar, sistemin özgüllüğünün 0.65 olmasına rağmen, benzer öksürük ses tanıma sistemlerinin sonuçlarına yakın görünmektedir.

\section{Sonuç}

Solunum hastalıklarını teşhis etmek için, klinik testlerin yüksek maliyeti, uzun geri dönüş süresi ve dünya çapında eşit erişim eksikliği göz önüne alındığında, uygun maliyetli, hızlı, kolay ve doğru bir yönteme sahip olmak esastır. $\mathrm{Bu}$ nedenle makine veya derin öğrenimine dayalı bir mobil uygulama veya hastaneler gibi kalabalık ortamlarda bu hastalıkların semptom seslerini taramak oldukça ilginç ve önemlidir. $\mathrm{Bu}$ çalışmada, OFSHOME tarafindan sunulan veri seti üzerinde, öksürük ve hapşırma seslerinden MFCC yöntemi ile öznitelikler elde edildi ve dört farklı sınıflandırıcı ile sınıflandırıldı. Bu veri seti üzerine daha önce herhangi bir çalışma yapılmadığından, bu çalışmanın bu alanda çalışanlar için 1şık tutacağını inanıyoruz. Ayrıca, ilerideki çalışmalar için, farklı öznitelik çıkarma teknikleri ve farklı sınıflandırıcılar kullanılarak elde edilen sonuçlarının iyileştirilmesi planlanmaktadır.

\section{Kaynakça}

[1] A. A. Saraiva et al., "Classification of respiratory sounds with convolutional neural network," Bioinforma. 2020 11th Int. Conf. Bioinforma. Model. Methods Algorithms, Proceedings; Part 13th Int. Jt. Conf. Biomed. Eng. Syst.
Technol. BIOSTEC 2020, pp. 138-144, 2020, doi: $10.5220 / 0008965101380144$.

[2] D. Sánchez Morillo, S. Astorga Moreno, M. Á. Fernández Granero, and A. León Jiménez, "Computerized analysis of respiratory sounds during COPD exacerbations," Comput. Biol. Med., vol. 43, no. 7, pp. 914-921, Aug. 2013, doi: 10.1016/J.COMPBIOMED.2013.03.011.

[3] M. Melek, "Diagnosis of COVID-19 and non-COVID-19 patients by classifying only a single cough sound," Neural Comput. Appl. 2021, pp. 1-12, Jul. 2021, doi: 10.1007/S00521-021-06346-3.

[4] U. R. Abeyratne, V. Swarnkar, A. Setyati, and R. Triasih, "Cough Sound Analysis Can Rapidly Diagnose Childhood Pneumonia,” Ann. Biomed. Eng. 2013 4111, vol. 41, no. 11, pp. 2448-2462, Jun. 2013, doi: 10.1007/S10439-013-08360 .

[5] V. Swarnkar, U. R. Abeyratne, A. B. Chang, Y. A. Amrulloh, A. Setyati, and R. Triasih, "Automatic Identification of Wet and Dry Cough in Pediatric Patients with Respiratory Diseases," Ann. Biomed. Eng. 2013 415, vol. 41, no. 5, pp. 1016-1028, Jan. 2013, doi: 10.1007/S10439-013-0741-6.

[6] M. Al-khassaweneh and R. B. Abdelrahman, "A signal processing approach for the diagnosis of asthma from cough sounds," http://dx.doi.org/10.3109/03091902.2012.758322, vol. 37, no. 3, pp. 165-171, Apr. 2013, doi: 10.3109/03091902.2012.758322.

[7] H. Chatrzarrin, A. Arcelus, R. Goubran, and F. Knoefel, "Feature extraction for the differentiation of dry and wet cough sounds," in MeMeA 2011 - 2011 IEEE International Symposium on Medical Measurements and Applications, Proceedings, 2011, pp. 162-166, doi: 10.1109/MeMeA.2011.5966670.

[8] E. Nemati, M. M. Rahman, V. Nathan, K. Vatanparvar, and J. Kuang, "A Comprehensive Approach for Classification of the Cough Type," in Proceedings of the Annual International Conference of the IEEE Engineering in Medicine and Biology Society, EMBS, Jul. 2020, vol. 2020-July, pp. 208212, doi: 10.1109/EMBC44109.2020.9175345.

[9] V. Bhateja, A. Taquee, and D. K. Sharma, "Pre-Processing and Classification of Cough Sounds in Noisy Environment using SVM," in 2019 4th International Conference on Information Systems and Computer Networks, ISCON 2019, Nov. 2019, pp. 822-826, doi: 10.1109/ISCON47742.2019.9036277.

[10] N. Simou, N. Stefanakis, and P. Zervas, "A universal system for cough detection in domestic acoustic environments," in European Signal Processing Conference, Jan. 2021, vol. 2021-January, pp. 111-115, doi: 10.23919/Eusipco47968.2020.9287659.

[11] F. Barata, K. Kipfer, M. Weber, P. Tinschert, E. Fleisch, and T. Kowatsch, "Towards device-agnostic mobile cough detection with convolutional neural networks," in 2019 IEEE International Conference on Healthcare Informatics, ICHI 2019, Jun. 2019, doi: 10.1109/ICHI.2019.8904554.

[12] "Center for Open Science." https://www.cos.io/? ga=2.107126978.1325905396.16318 83086-1696097544.1629751041 (accessed Sep. 17, 2021). 
[13] "OSF | Dataset of sounds of symptoms associated with respiratory sickness Wiki." https://osf.io/tmkud/wiki/home/ (accessed Sep. 17, 2021).

[14] R. Gonzalez, "Better Than MFCC Audio Classification Features," Era Interact. Media, vol. 9781461435013, pp. 291-301, Oct. 2013, doi: 10.1007/978-1-4614-3501-3_24.

[15] M. A. Hossan, S. Memon, and M. A. Gregory, "A novel approach for MFCC feature extraction," 4th Int. Conf. Signal Process. Commun. Syst. ICSPCS'2010 - Proc., 2010, doi: 10.1109/ICSPCS.2010.5709752.

[16] Y. Wang and B. Lawlor, "Speaker recognition based on MFCC and BP neural networks," 2017 28th Irish Signals Syst. Conf. ISSC 2017, Jul. 2017, doi: 10.1109/ISSC.2017.7983644.

[17] A. Winursito, R. Hidayat, and A. Bejo, "Improvement of MFCC feature extraction accuracy using PCA in Indonesian speech recognition,” 2018 Int. Conf. Inf. Commun. Technol. ICOIACT 2018, vol. 2018-January, pp. 379-383, Apr. 2018, doi: 10.1109/ICOIACT.2018.8350748.

[18] N. Melek Manshouri, "Identifying COVID-19 by using spectral analysis of cough recordings: a distinctive classification study," Cogn. Neurodynamics 2021, pp. 1-15, Jul. 2021, doi: 10.1007/S11571-021-09695-W.

[19] K. S. (Krothapalli S. Rao and Manjunath K. E., "Speech recognition using articulatory and excitation source features," p. 92.

[20] M. Melek, N. Manshouri, and T. Kayikcioglu, "Low-Cost Brain-Computer Interface Using the Emotiv Epoc Headset Based on Rotating Vanes," Trait. du Signal, vol. 37, no. 5, pp. 831-837, Nov. 2020, doi: 10.18280/ts.370516.

[21] U. Ozkaya, F. Melgani, M. B. Bejiga, L. Seyfi, and M. Donelli, "GPR B scan image analysis with deep learning methods," Measurement 2020, 165, 107770. doi: 10.1016/j.measurement.2020.107770. 